\title{
CORRESPONDENCE
}

them particularly vulnerable and suggestible, presenting with more and more unusual or bizarre methods of self-harm.

Huang M. P. \& Alessi, N. E. (1996) The Internet and the future of psychiatry. American Journal of Psychiatry. 153, 861-869.

SuRESH. K. \& LYNCH. S. (1998) Psychiatry and the WWW: some implications. Psychiatric Bulletin. 4. 256-266.

F. HAUT, Specialist Registrar, and A. MORRISON, Senior Registrar, Dundee Healthcare NHS Trust, Teaching and Research Division, Royal Dundee Liff Hospital, Dundee DD2 5NF

\section{Management of cognitive impairment of vascular origin}

Sir: The study carried out by Michael Dennis \& Ann Boyle (Psychiatric Bulletin. May 1998, 22. 285-287) showed a clear consensus that aspirin is generally seen as an important strategy for the management of cognitive impairment of vascular origin.
The European Stroke Prevention Study 2 (Diener et al, 1996) clearly concludes that dipyridamole in a modified release at a dose of $200 \mathrm{mg}$ twice daily and low-dose aspirin have each been shown to be equally effective for the secondary prevention of ischaemic stroke and transient ischaemic attacks, and when coprescribed the protective effects are additive, the combination being significantly more effective than either agent prescribed singly. This was a randomised placebo controlled, double-blind trial involving over 6000 patients. In clinical practice therefore we should be considering the use of low-dose aspirin in combination with dipyridamole.

Diener, H. C., Cunha, C., Forbes, C., et al (1996) European Stroke prevention Study 2. Journal of Neurological Sciences, 143, 1-13.

C. ANDREwS, Senior Registrar on Old Age Psychiatry, Health Care of the Elderly Directorate, Queen's Medical Centre, Highbury Hospital, Highbury Road, Bulwell, Nottingham NG6 9DR

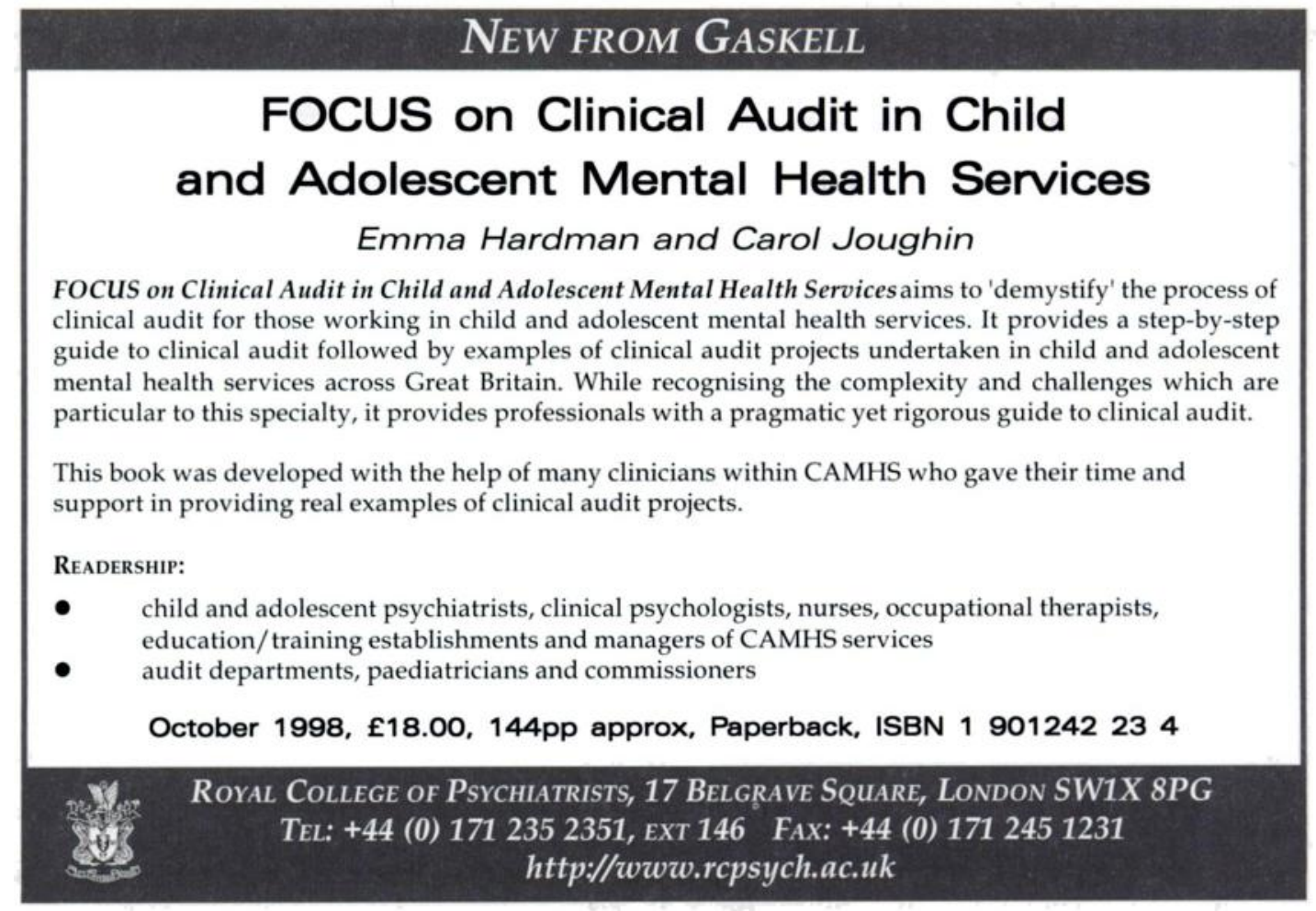

